This item was submitted to Loughborough's Research Repository by the author.

Items in Figshare are protected by copyright, with all rights reserved, unless otherwise indicated.

\title{
An observational comparison of the older and younger bus passenger experience in a developing world city
}

\section{PLEASE CITE THE PUBLISHED VERSION}

http://dx.doi.org/10.1080/00140139.2015.1091513

\section{PUBLISHER}

(C) Taylor and Francis

\section{VERSION}

AM (Accepted Manuscript)

\section{PUBLISHER STATEMENT}

This work is made available according to the conditions of the Creative Commons Attribution-NonCommercialNoDerivatives 4.0 International (CC BY-NC-ND 4.0) licence. Full details of this licence are available at: https://creativecommons.org/licenses/by-nc-nd/4.0/

\section{LICENCE}

CC BY-NC-ND 4.0

\section{REPOSITORY RECORD}

Aceves-Gonzalez, Carlos, Andrew May, and Sharon Cook. 2015. "An Observational Comparison of the Older and Younger Bus Passenger Experience in a Developing World City”. Loughborough University. https://hdl.handle.net/2134/19927. 


\title{
An observational comparison of the older and younger bus passenger experience in a developing world city
}

\author{
Carlos Aceves-Gonzalez ${ }^{1}$, Andrew May², Sharon Cook ${ }^{3}$ \\ Loughborough Design School, Loughborough University, Loughborough, LE11 3TU \\ ${ }^{1}$ [C.Aceves-Gonzalez] ${ }^{2}$ [A.J.May] ${ }^{3}$ [S.E.Cook] @lboro.ac.uk \\ *Corresponding author: Andrew May, Tel +44 1509226900
}

\begin{abstract}
This study was an unobtrusive observational analysis of 333 older and younger bus passengers in Guadalajara, Mexico. A set of data were collected for each observed passenger, as well as more general observations related to driver behaviour, bus design, and bus service characteristics. There were significant differences between older and younger passengers in terms of boarding and alighting times, use of handrails, seat location preferences, passenger stability and coping strategies in order to maintain postural stability. The conditions of travel are conducive to a poor passenger experience for the older passengers in particular. Although the problems may be attributed to bus design and driver behaviour typical of that in developing countries, they are also influenced by the wider transport infrastructure, and a lack of a regulatory regime which places drivers under time pressure, and in direct competition with each other.
\end{abstract}

Keywords: developing world; bus passenger; observational study; traveller experience; public transport, driver behaviour, bus design

Practitioner Summary: Bus services must cater for all ages of passengers, including the elderly. This unobtrusive observational study investigated the passenger experience in a developing world city. Bus and wider service design were found to compromise the journey experience, with the older users being particularly negatively impacted. Design recommendations are provided. 


\section{Introduction}

\subsection{Background}

The ageing of the world's population that initially occurred in the more developed countries, is now becoming more evident in much of the developing world, where the economic and social impact is expected to be considerable due to the rapid rate of ageing (United Nations 2010; United Nations 2002). The World Health Organization (WHO 2002) argues that countries 'can afford to get old' if governments and society enable 'active ageing' of their populations through policies and programs to maintain and improve the health, social participation and security for older people.

The discipline of ergonomics/human factors has a key role to play in ensuring that products and services meet the needs of the older population (Dul et al. 2012). Transport, and particularly public transport, is important for 'active ageing' and has been linked to accessibility and usability problems for older and disabled people (Broome et al. 2009). The World Health Organization (WHO 2007) specifically highlights how services such as transport have difficulty in meeting the needs of older citizens. Although legislation in developed countries such as The Disability Discrimination Act (DDA 1995) - now replaced by The Equality Act, 2010 - and The Americans with Disabilities Act (ADA 1990) has promoted universal access and mobility, these regulatory drivers are not in place in the developing world and public transport provision is governed largely by market forces. These may, or may not, work in the interests of older passengers. Increasing universal access to public transport is a key means of ergonomics contributing to a more sustainable future, and this article hopes to make a specific contribution in this respect, as called for by Haslam and Waterson (2013).

There have been several studies of the difficulties faced by older bus passengers in the developed world. These have identified physical issues related to boarding, alighting, route design, fear of falling and wider issues to do with service design and availability - e.g. Rogers et al. (1998); Davey (2006); Peel, Westmoreland and Steinberg (2002). Fewer studies have investigated older passenger bus use in the developing world. Ipingbemi (2010) used questionnaires to identify issues relating to waiting times, difficulty in boarding due to physical bus design and intolerance from drivers. An extensive set of multinational focus groups by the World Health Organization (WHO 2007) found a range of issues for older bus 
users in the developing world, including unreliable service, high steps, lack of respect for priority seating, insensitivity of drivers, and crowded buses.

In a rare direct comparison of older and younger passenger experiences, Broome et al. (2010) used a nominal group technique to identify differences in priorities for critical bus use barriers and facilitators, and also how these were perceived and described. The attitude and behaviour of the bus driver was of far greater importance to the older passengers.

Despite the work above, there is a lack of published research comparing explicitly older and younger bus passengers within the developing world. This results in difficulty in analysing the interaction between the limitations of older passengers and the demands imposed by the transport system. Service stakeholders (who include drivers, bus operators, bus manufacturers, designers and regulators) will be younger than their pension-aged passengers, and are unlikely to directly experience for themselves the challenges such passengers face in using the bus. In addition, most of these stakeholders (aside from the drivers) are not in direct contact with such passengers and cannot identify where aspects of the service impact specifically on older passengers.

From a methodological perspective, the vast majority of reported studies of older bus users have used self-report methods - e.g. focus groups by Rogers et al. (1998); semi-structured interviews by Davey (2006); interviews by Peel, Westmoreland and Steinberg (2002); questionnaires by Ipingbemi (2010) - as the primary source of data. Although these are useful since they convey beliefs and attitudes relating to the service, they lack the objectivity in data collection that is desirable, particularly in terms of presenting evidence to stakeholders to promote service improvement. Broome et al. (2009) highlight how views stated in relation to subjective experience, while important, might be disproportionate to reality. In contrast, performance observations or measures allow an objective assessment of passengers' behaviour and a comprehensive view of the variation between population groups (Sainio et al. 2006). This helps overcome the limitations of self-report discussed by Hammersley (1990) and enables analysis of what passengers actually did within their specific context of use (Paterson, Bottorff and Hewat 2003).

\subsection{Aim and objectives}

The aim of this study was to understand how the current design of the buses and the wider service impact differentially on younger and older passengers in their use of the bus, within the context of a developing city. Specific objectives of the study were to: 
- Investigate actual passenger behaviour when boarding, travelling on, and alighting buses in Guadalajara, Mexico

- To identify key bus design and service characteristics that have an impact on passengers' behaviour

- To compare the behaviour of, and differential impact on, older and younger passengers in order to identify where future improvements to the inclusive design of the service will most benefit older users

\section{Method}

\subsection{Participants}

Participants consisted of 333 bus passengers, who used the bus service during 49 observational sessions undertaken within a four week period. One hundred and eighty nine (57\%) of them were judged as aged between 18 and 50, and were termed 'younger'. One hundred and forty four (43\%) were judged as aged 60 and over and were termed 'older'. The age of passengers was estimated on the basis of appearance and physical capabilities, and also whether the passenger used a travel concession which was available to those aged over 60. Passengers who appeared to be aged between 50 and 60 were not included in the observation, to increase the reliability of the age categorisation. The study required that observation was discreet and therefore more accurate self-report could not be used. However, age estimates have been used reliably in previous studies with observational methodologies, e.g. see Zeedyk and Kelly (2003).

\subsection{Observation method and framework}

This study used a purely unobtrusive method of anonymous data collection, without any awareness of the individuals involved in delivering or using the service. Although this had limitations (discussed in section 3.8), it ensured that all behaviours observed were entirely naturalistic. Based on the review of previous work, an observation framework (Figure 1) was developed for this study, incorporating the 'performance and well-being' focus described by Dul et al. (2012). This linked aspects of passenger behaviour with stages of the journey connected to bus use, and included non-temporal aspects of behaviour, and other service and contextual factors of interest. 


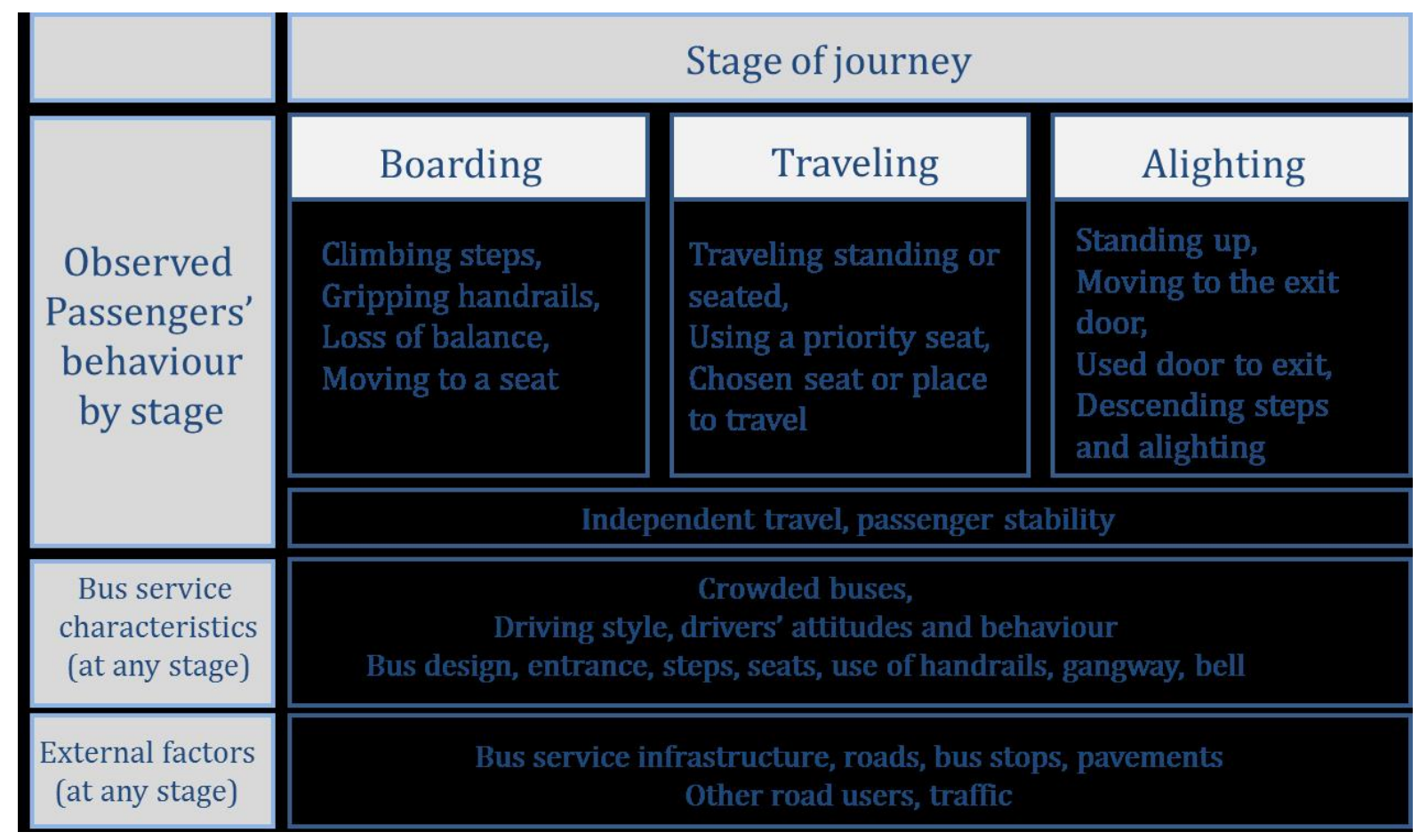

\section{Figure 1. Observation framework used for data collection}

Specifically, the following details were recorded for each passenger observation:

Climbing steps. Observed physical difficulty; whether passengers boarded from the road level or pavement.

Gripping the handrails. While climbing steps, making payment, or moving to a seat; whether one or two hands were used.

Loss of balance. Evidence of the presence or absence of a protective response to a loss of balance, such as movements of both upper and lower extremities including grasping, arm swing, and compensatory stepping (Redfern et al. 2001). Observed when a passenger was climbing the steps, paying and moving to a seat.

Boarding the bus. Time for boarding measured from the bus driver opening the front door until the passenger was seated, or at their standing location; whether the driver drove off before the passenger was seated or had moved to their final standing position; whether passenger was boarding at a red light (i.e. involuntary waiting). 
Traveling standing or seating. Whether passenger was traveling standing or seated, after they had paid and moved to a seat or the final standing position; whether seats were available (for a standing passenger); movement between seats.

Using a priority seat. Use of a priority seat (by all passengers); whether priority seats were already occupied and therefore unavailable.

Chosen seat (or place if standing). The number of the seat, or location if standing.

Alighting the bus. Time for alighting measured from the passenger standing up from the seat (or starting to move from their standing position) until they stepped onto the road or pavement with both feet; the door used for disembarking; use of the bell.

Independent mobility. Whether a passenger was using a mobility aid; whether a passenger was: (1) travelling on their own and without any assistance from a third person, (2) travelling accompanied, but without requiring any assistance from a third party, (3) accompanied and needed or received help to complete the task at any stage using the service. For this purpose 'help' was defined as any physical support provided by a third person, e.g. holding a hand when boarding or alighting, or supporting any part of the body for postural control.

In addition a number of passenger independent observations were made relating to: driving style and other behaviour (e.g. not stopping adjacent to the kerb), bus design (height and configuration of steps, location and height of handrails, seat layout, and bell position), level of overcrowding on the bus, and passenger stability based on a judgement of how smooth the journey was and other relevant details impacting on passenger comfort and/or safety (e.g. presence of bus stops, pavement conditions).

\subsection{Observational instrument}

An A5 formatted template was used to record a set of data for each observed passenger. This comprised data fields as above, a graphic of the seat layout in the bus, and a free-form section for non-coded observations. It was developed after pre-tests and then a full pilot capturing data on 12 younger and 26 older bus passengers in the UK. The pilot also determined that a maximum of three passengers should be observed at any one time, in order to maintain data quality. 


\subsection{Procedure}

Observations were conducted on 17 major urban bus routes run by different bus operators, running along the busiest traffic corridor in the city of Guadalajara, from the north-western to the eastern outskirts, via the city centre. A total of 49 observational sessions were undertaken, all on weekdays between 07.00 and 20.00 over a four-week period. The experimenter sat discreetly in the middle of the bus for maximum visibility of the driver and passengers, who were both unaware of the presence of the experimenter, or the existence of the study, although permission to undertake the study had been obtained from the bus operator managers.

Passengers were observed and details taken as they boarded the bus; observation of that passenger continued until they alighted. Due to the crowded nature of the buses and real time data collection it was not always possible to collect a full data set for each passenger observed - for example it was only possible to collect boarding times for 106 and alighting times for 124 of the 144 older passengers who were observed. In addition, due to safety considerations, observations were only undertaken when the experimenter could be seated, which resulted in reduced data collection during periods of maximum overcrowding.

\section{Results and discussion}

\subsection{Bus design}

There are around 5000 buses operating in the city of Guadalajara. With the exception of only 10 low entry buses, they are single decker, typically built on an adapted truck chassis, with the engine at the front and manual gearchange, a length of about $8.4 \mathrm{~m}$ and with 28 seats. There is normally a straight flight of four steps and guide rail at the front entry door and the rear exit door; the height of the first step is not more permitted to be more than $0.4 \mathrm{~m}$, the remainder being around $0.25 \mathrm{~m}$, and the floor height around $1.1 \mathrm{~m}$ above road level. A typical bus and seating configuration is shown in Figures 2 and 3, with the single row of seats also allowing up to 58 standing passengers. 


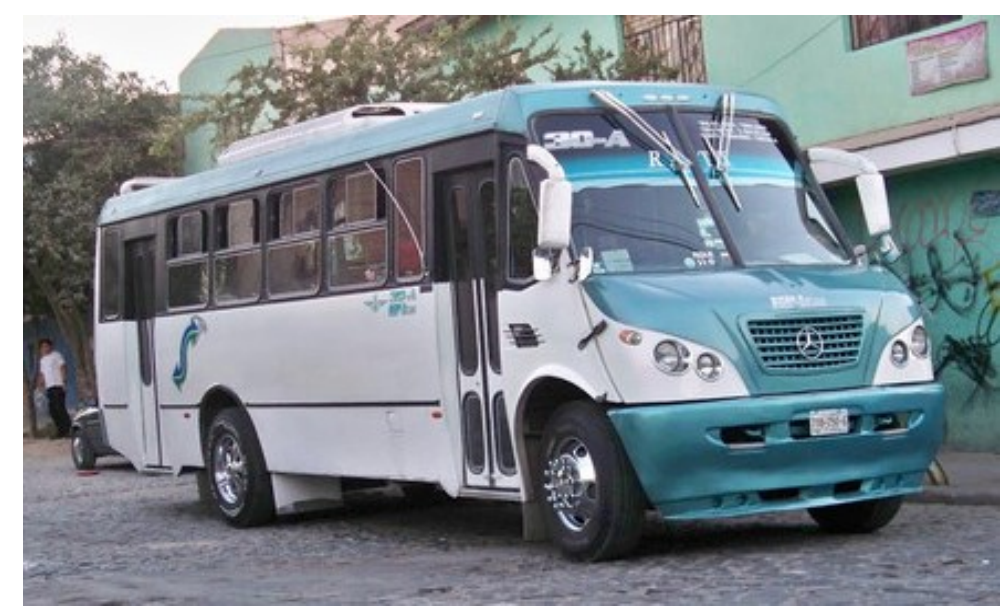

Figure 2. Typical bus design

The first three seats are colour coded 'priority' seats, reserved for pregnant women, disabled and older passengers. Handrails run horizontally along both sides of the bus gangway at a height of approximately of $1.75 \mathrm{~m}$. Vertical handrails are situated near to the front and rear doors. A single bell is placed on the vertical handrail close to the back door at a height of approximately of $1.7 \mathrm{~m}$.

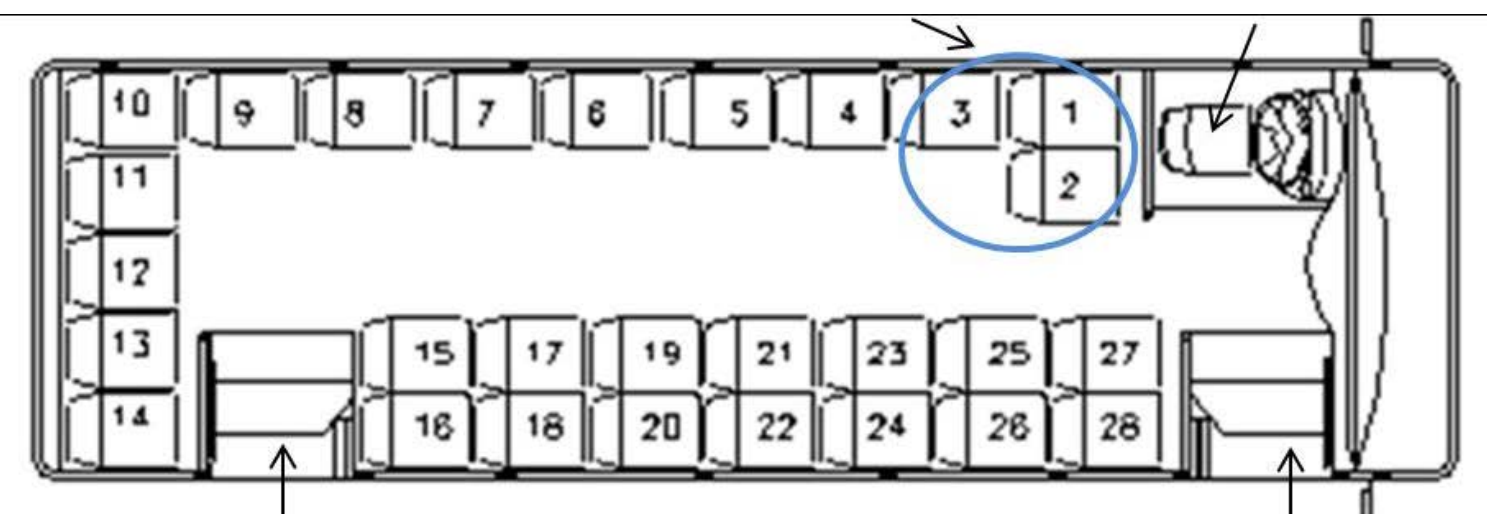

Figure 3. Typical bus seat layout

\subsection{Passenger stability}

A judgement was made by the investigator of the stability of each observed journey. Only $14 \%$ were considered 'smooth' over their entirety, and over 50\% had frequent and extended periods where there was considered excessive lateral, longitudinal or vertical acceleration, 
and resulting passenger instability. The stability of a journey depends on acceleration or deceleration, which is determined mainly by the driving skills (Karekla and Tyler 2012) and style employed (e.g. sharp acceleration away from bus stops). However, this was exacerbated by poor road surfaces, stiff suspension due to the truck chassis, the manual gear-change, road design and heavy traffic conditions. There were no dedicated bus lanes and bus drivers had to compete with other drivers for a place in the traffic. According to Levis (1978) comfort, stability and safety of all bus passengers is affected by the acceleration experienced in the vehicle. The stability of a journey is not a characteristic frequently reported as barrier to using the bus service. However, previous studies have generally explored the use of buses through self-report methods (Broome et al. 2009) or laboratory experiments (Karekla and Tyler 2012) which do not allow observation of actual journeys. Furthermore, most of the reported studies have been undertaken in developed countries where bus design and/or road conditions are likely to be different to those in developing countries.

\subsection{Driver behaviour}

In the context of the general lack of passenger stability described above, it was observed that in only approximately $10 \%$ of journeys was the bus driven in a similar manner to the pilot study undertaken in the UK. The actions of the drivers indicated they were driving under time pressure, and also with high workload, since they were undertaking the payment process with passengers while negotiating their place in the traffic. Drivers very infrequently stopped adjacent to the kerb. This made it more difficult for passengers, especially for older ones, since they were then boarding or alighting the bus from/to the road level and thus contending with a greater initial step height. This problem was also observed by Petzäll (1993), and it has been reported as a barrier to using the bus service by older people (Peel et al. 2002; WHO 2007). However, this was not always the decision of the driver, due to passengers waiting in the road, cars parked at or near bus stops which made it impossible to stop the bus adjacent to the pavement, and a lack of official bus stops or raised pavements at some locations.

Drivers allowed little time for passengers to board or alight, and on some occasions only slowed down (and did not actually stop), therefore forcing passengers to physically jump onto or off the bus. Drivers often pressurised the passengers to board or alight as quickly as possible, and consistently drove away immediately after picking up passengers, before they were seated. This occurred in $88 \%$ of the observations, the majority of the exceptions being when the bus had to wait at a bus stop located at a traffic light controlled junction, or when following passengers were boarding. In only $2 \%$ of observations did the driver purposefully 
wait for a passenger to be seated before departing. As well as making it difficult for boarding, paying, and moving to a seat, this situation raises safety concerns, particularly in relation to older passengers. Nickpour, Jordan and Dong (2012) found that driving away before passengers are seated was reported as barrier to using the bus service in London.

Much of the drivers' behaviour can be explained by the lack of a regulatory and legislative regime in the city, where the existence of 'informal' procedures within the bus system and drivers being paid directly out of the fares they collect, results in lack of scheduled services. This therefore results in competition between drivers, and a 'race' to pick up passengers. Bus operators therefore compete instead of collaborating to provide an inclusive service within the city (Gutiérrez-Pulido et al. 2011). Similar conditions have been reported in cities like Dhaka and Bangladesh (Katz and Garrow 2012).

\subsection{Boarding and alighting}

It was observed that the older passengers had greater difficulty climbing and descending the steps than the younger passengers, and $60 \%$ of the older passengers were observed placing both feet on at least one tread, when either boarding or alighting. Approximately $30 \%$ of the older passengers had to make considerable effort to climb the first step in particular, which is consistent with findings reported by Petzäll (1993). This problem was exacerbated when passengers had to transition to or from the road level, where the height of the first step from road level is commonly $400 \mathrm{~mm}$ - double the recommended dimensions of 150-200 mm (Petzäll 1993), and in comparison to the low floor buses introduced in developed countries. Not surprisingly difficulties boarding and alighting buses have been widely reported as a barrier to using a bus service (Broome et al. 2009). It was estimated (but not recorded formally) that about $30 \%$ of the older passengers had to turn rearwards to be able to descend the last step.

All bar one older passenger (99\%) and a surprisingly high percentage of younger passengers (78\%) were observed using the handrails while boarding the bus (i.e. up to being seated, or in the final standing position). However, despite this high percentage for the younger passengers, there is still a significant difference based on a Chi-square test for independence (with Yates Continuity Correction), $\chi^{2}(1, \mathrm{n}=328)=30.53, p<.001$, $p h i=.31$. Using a handrail is a compensatory strategy to mitigate disability and increase stability (Reid et al. 2011). According to Startzell and Owens (2000) a handrail enables the user to slide their hand to monitor progress, it can be used as a means of reducing the load on the lower extremities (e.g. 
when ascending steps), and it also helps as a device to prevent falls after a misstep or slip. Handrails have been also described as a multipurpose tool that provides both physical and psychological support (Reid et al. 2011).

A clear difference was observed in the way hand supports were gripped and used by the older and younger passengers. With one exception (when the bus was stationary), all older passengers used hand support at each stage of boarding, paying, and moving to their seat. The behaviour typically observed during ascending and descending was for the older passengers to grasp firmly the rails adjacent to the steps, to move their grasp prior to stepping, and then to use the handrails to help pull themselves up the steps on boarding, and to support some of their weight when descending the steps on alighting. This was particularly apparent when ascending the first step, where the lack of a raised pavement required a passenger to negotiate a step height of approximately $400 \mathrm{~mm}$. This use of the upper body compensates for the loss in knee extensor strength due to ageing (Goodpaster et al. 2006), and/or to reduce the forces in the knee when climbing or descending steps. Peat, McCarney and Croft (2001) describe how knee joint pain (of various attribution, including osteoarthritis) is suffered by $25 \%$ of those over 55. Stair climbing generates much greater contact forces in the knee than does walking, and these additional forces can cause pain for even patients with early osteoarthritis (Costigan, Deluzio and Wyss 2002). In contrast, the younger passengers tended to use the handrails at the entry and exit doors as general support, using only one hand. It was noticeable that younger passengers were also required to use two hands for postural support when the drivers departed or slowed abruptly causing longitudinal instability.

Due to the crowded buses, passengers who wished to alight generally had to stand up and start moving through the bus before it had stopped. Taller passengers were able to use the horizontal handrails at $1.75 \mathrm{~m}$; however shorter passengers were required to use the seat backs for support, and these were inaccessible when the buses were crowded. Crowded buses have also been related to difficulties in finding and pressing the bell (Hwangbo et al. 2012), and more generally using the bus service by older people (WHO 2007). The in-bus signage stated that the front door should be used for boarding, and the rear for alighting. However $20 \%$ of the younger and over $70 \%$ of the older passengers used the front door for alighting (despite driver attempts at dissuasion), a highly significant difference, $\chi^{2}(1, \mathrm{n}=239)=60.59, p<.001$, phi $=-.51$. This is consistent with the experiences of the investigator when living and working in the city - that older participants report feeling unsafe using the rear door to alight, as they are then not visible to the driver. 
Figure 4 shows a frequency distribution of the boarding and alighting times as defined above.
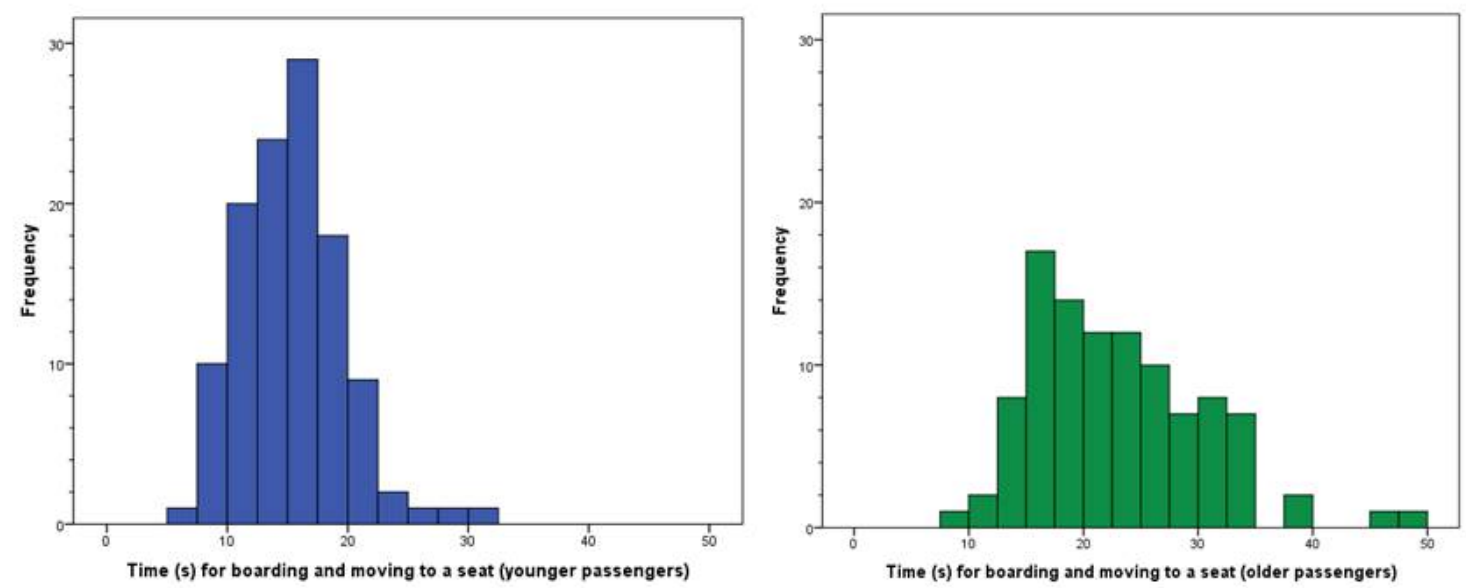

Figure 4. Distribution of younger and older passenger boarding times

Figure 5 shows how boarding time varied according to passenger age and seat position. For each bar, the box shows the median and interquartile range (IQ), the whiskers the highest and lowest values excluding the outliers, circles are 'outliers' (>1.5IQ from either box end), and stars are 'extreme values' (>3IQ from either box end). 


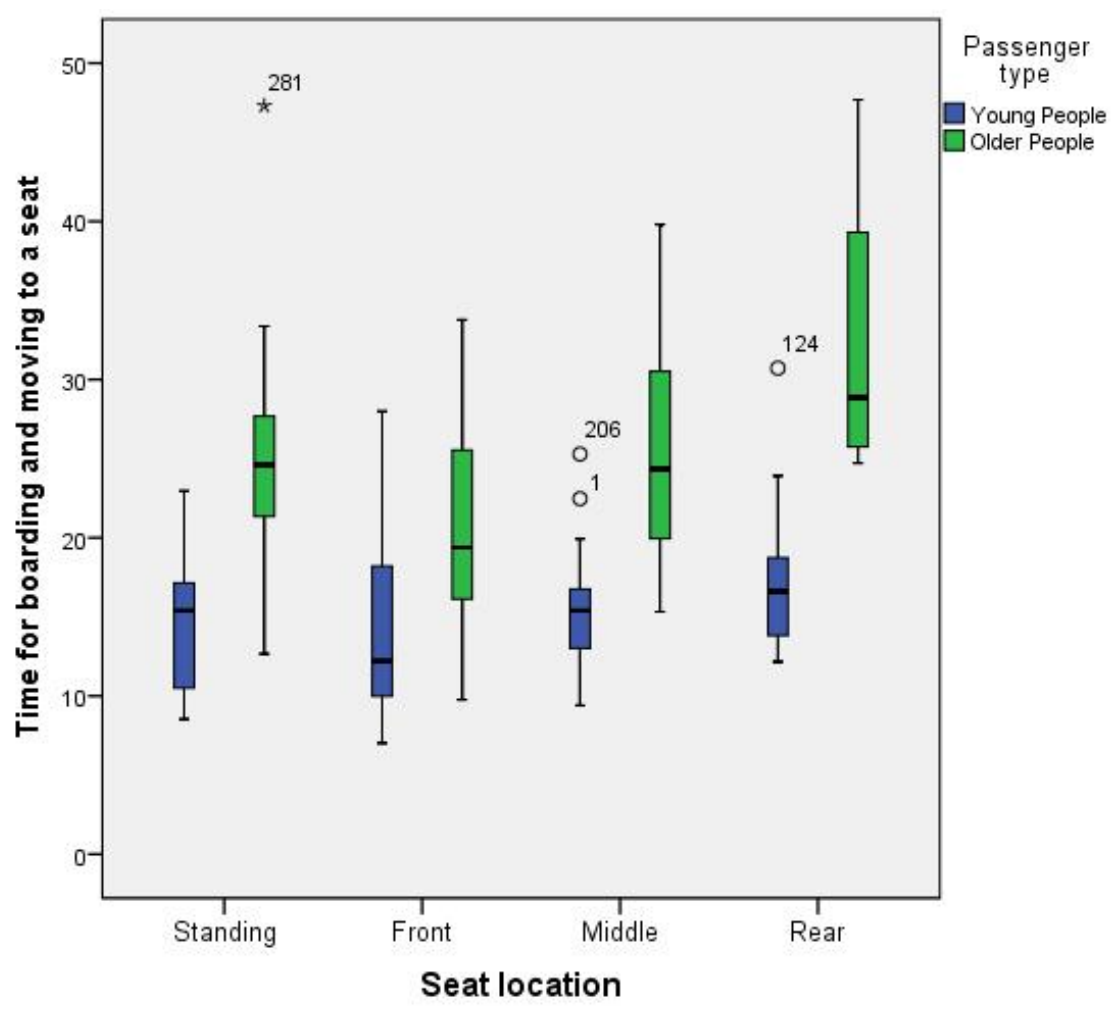

Figure 5. Boarding times based on seat location

The distribution for the older passengers is positively skewed, and following the recommendations of Osborne and Overbay (2004) four outliers were deleted - to the extent that the Kolmogorov-Smirnov test result for normality became non-significant (Pallant 2013). Results from the Levene's test for equality suggested that variances of the two groups were not equal and therefore the assumption of homogeneity of variance was violated. However, as Stevens (2009) indicates, the $F$ statistic is robust against heterogeneous variances when the group sizes are similar (largest/smallest $<1.5$ ).

A 2-way analysis of variance was calculated to analyse the effects that the seat location (standing, front, middle, rear) and type of passengers (younger and older) had on the time for boarding the bus. There was a main effect of passenger type $(F(1,210)=102.97, p<.001)$ and seat location $(F(3,210)=6.73, p<.001)$. There was no significant differential impact $(F$ $(3,210)=2.60, p=.053)$ of seat location with age on boarding time.

A similar analysis was undertaken for the alighting times. Figure 6 shows the overall distribution of alighting times for the older and younger passengers, and Figure 7 the alighting times according to seating position. 

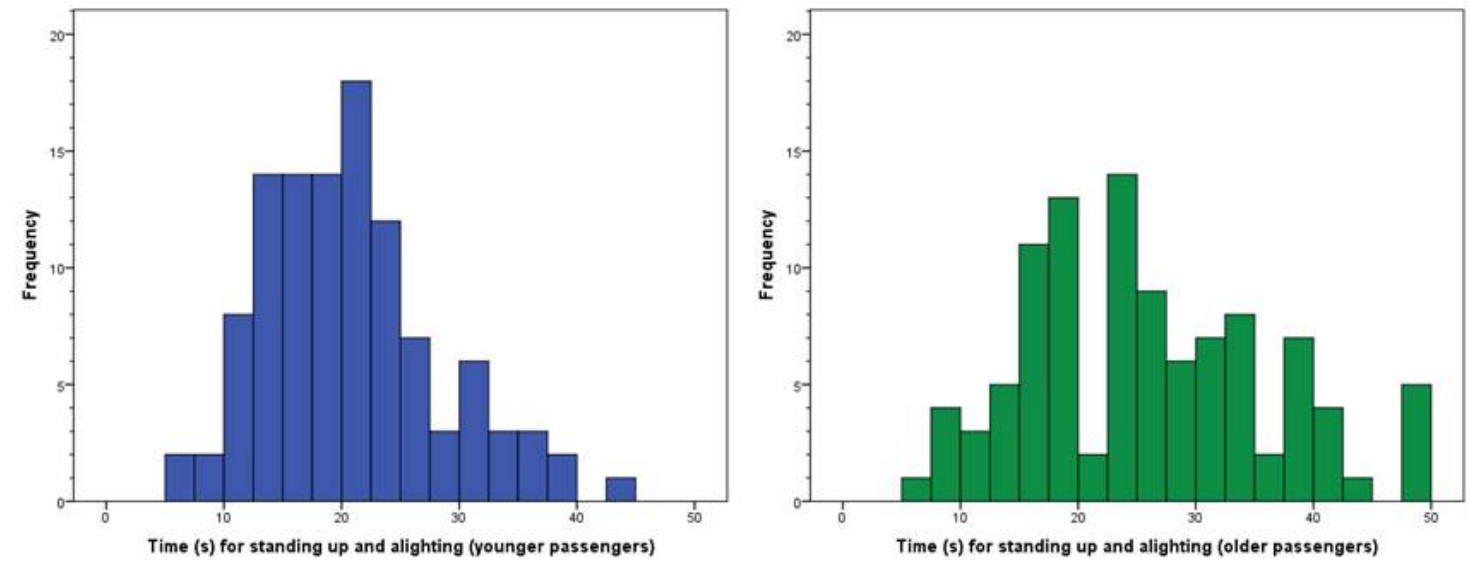

Figure 6. Distribution of younger and older passenger alighting times

As above, 11 and 18 outliers were removed for the younger and older passengers respectively to normalise the data (Osborne and Overbay 2004).

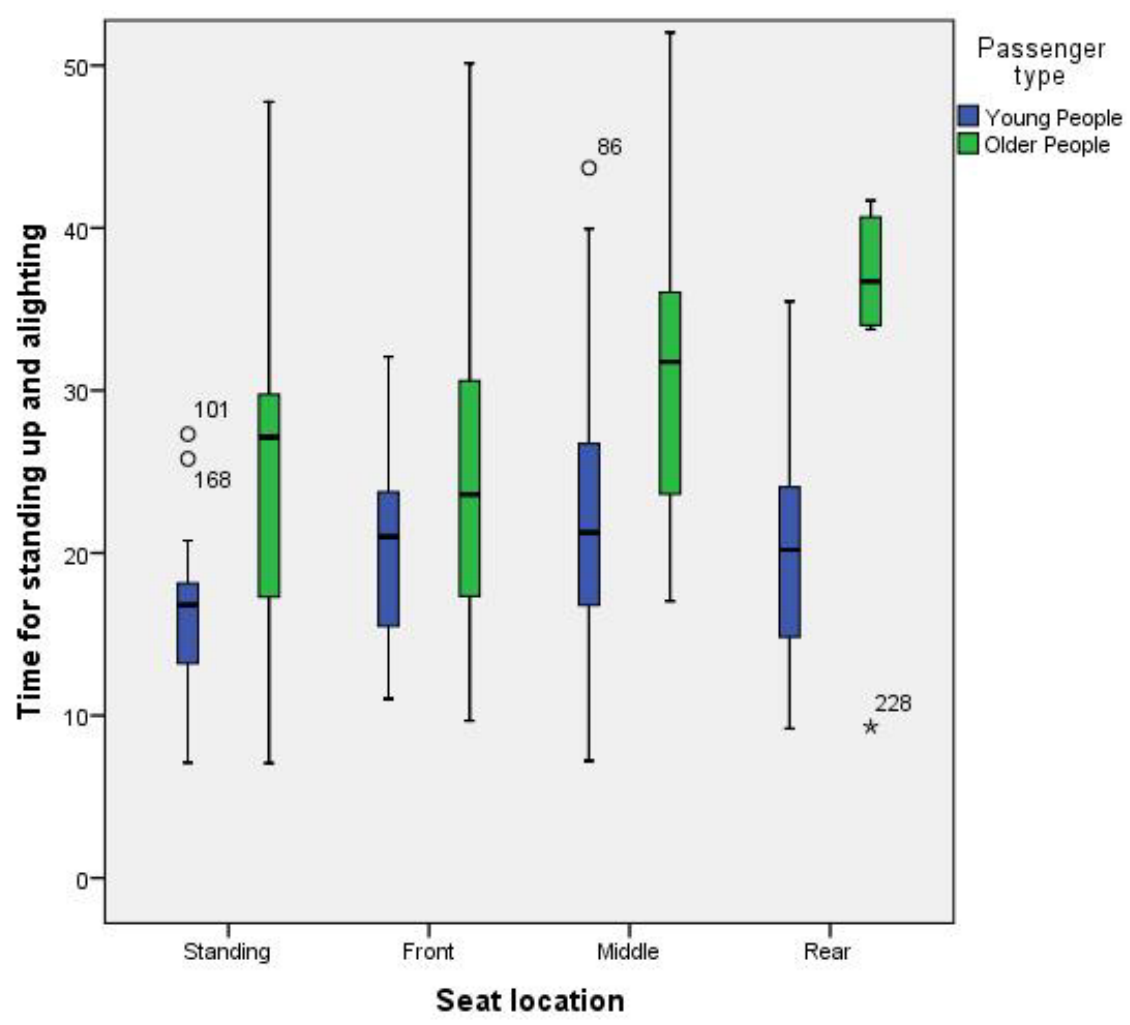

Figure 7. Alighting times based on seat location 
Using similar analysis as above, there was a main effect of passenger type $(F(1,215)=36.15$, $p<.001)$ and seat location $(F(3,215)=4.11, p<.01)$ on the time to alight from the bus. There was no significant differential impact $(F(3,215)=2.03, p=.11)$ of seat location with age on alighting time.

The findings above are in line with previous research that has suggested that older people with a fear of falling (Tiedemann, Sherrington and Lord 2007), or decreased confidence in stair negotiation (Hamel and Cavanagh 2004) are likely to ascend and descend stairs more slowly than their young counterparts. The most striking difference in Figure 7 is that the older passengers took in general approximately twice as long to alight than the younger passengers when seated at the rear. This is due to the older passengers' preferences for alighting from the front door, described above.

Both young and older passengers took longer alighting than boarding. These findings seem inconsistent with those by Reid et al. (2011) who found that stair ascending is slower than descending; however the somewhat contradictory result may be due to the time for boarding and alighting in this study being measured to include movement to and from seats. There is also greater variability associated with alighting, reflecting the various anticipatory strategies employed, especially by the older passengers. For instance, older passengers were observed to move progressively further forward in the bus as seats became free so that they were closer to the front door when the time came for them to alight.

The fact that older passengers board and move to a seat more slowly than the younger passengers actually has little effect on the efficiency of the bus service because drivers do not wait for passengers to be seated before departing. However, this may have a major impact on older passenger safety due to their greater exposure to the risk factors for losing their balance and possibly suffering a fall. Older people are particularly vulnerable to non-collision bus injuries (Palacio et al. 2009).

\subsection{Passenger loss of balance}

Decrease in postural control in older people is believed to be an important factor in the likelihood of a fall (Redfern, Moore and Yarsky 1997). Fifty-six percent of older passengers and 35\% of younger passengers were observed losing their balance (as defined in Section 2.2) when boarding the bus and moving to a seat, due to the acceleration and deceleration of the bus described above. This represents a statistically significant difference, $\left(\chi^{2}(1, n=238)=\right.$ 10.03, $p<.01$, phi $=.21$ ), and is in line with existing research which reports that older 
individuals are less stable during standing, and do not perform as well as young people on obstacle clearance, postural perturbation or other motor control tasks (see Maki and McIlroy [1996]; Startzell and Owens [2000]).

The instances of loss of balance occurred mainly when passengers were paying the driver or when moving to a seat. It was observed that passengers had difficulty taking cash from their wallets or purses, passing payment to the driver, and grasping the handrails and their belongings at the same time. Indeed, some older passengers exhibited alternative behaviours such as placing their belongings on the floor while they were paying, or moving to the nearest seat, setting down their belongings and then paying the driver. However, the underlying cause of passengers losing their balance was the fact that drivers drove off before passengers were seated.

\subsection{Independent mobility}

Contrary to expectations, results from this study show that similar percentages of older (15\%) and young people (14\%) passengers were travelling unaccompanied. Additionally, although there was a significant difference between the number of younger $(0 \%)$ and older (4\%) passengers who received additional assistance (two tailed Fisher's exact test, $p=0.06$ ), for older passengers this only represents four of the older passengers who were travelling accompanied and two who were travelling unaccompanied.

These results suggest that virtually all of the passengers observed (younger and older) were able to use the service independently, as defined in Section 2.2 This appears to show that the bus service allows older people to travel unaccompanied and without assistance. However only $5 \%$ of older passengers in this study were observed using any form of mobility aid. Figures from the National Institute of Statistics and Geography in Mexico show that 18\% of older people suffer from mobility problems (INEGI 2013), this percentage being consistent with Agree et al. (2004) who state that (in the context of the USA) 'mobility limitations are a common problem affecting up to $16 \%$ to $20 \%$ of the older population, depending on the measure used'. The majority of older persons with mobility problems use assistive devices (Agree, Freedman and Sengupta 2004). Based on the discrepancy between the number of passengers observed with mobility aids, and the percentage of the general older population who use them, the data suggest (but cannot show definitively) that a sizeable proportion of individuals with mobility impairments do not use the bus service. It was observed that it was 
particularly difficult for those using a mobility aid to use the buses, as they were then prevented from grasping the handrail or seat back with two hands.

\subsection{Chosen seat or place to travel}

Differences were also observed in the region of the bus where young and older passengers chose to sit, based on a distinction between front, middle and rear seating, plus traveling standing. Figure 8 shows the percentage of young and older passengers who were seated or traveling in each of those areas. Using a Chi-square test for independence, there were clear differences between the younger and older passengers, $\chi^{2}(3, \mathrm{n}=333)=70.45, p<.001$, phi $=.46$.

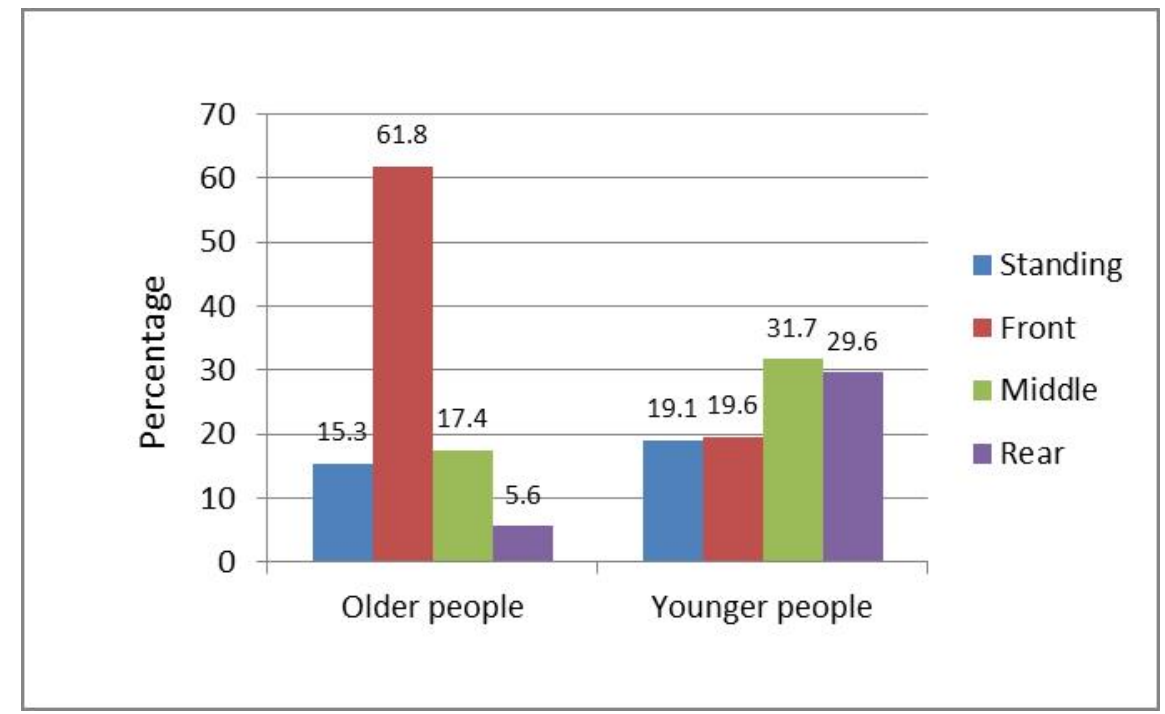

Figure 8. Chosen seat or place to travel for older and younger passengers

The first three seats were normally 'priority seats' reserved for pregnant women, disabled and older passengers. Forty-seven percent of observed older passengers and only 5\% of observed younger passengers were seated in these positions, a significant difference, $\chi^{2}(1, n=333)=$ 78.28, $p<.001$, $p h i=.49$. It was observed that younger passengers generally did not take a priority seat when there were additional seats available; however, when buses were crowded younger passengers tended to use those seats more, even when some older passengers were boarding or traveling standing. On 35\% of occasions where an older person was boarding the bus, at least one of the three priority seats was occupied by a younger passenger. On only very few occasions was it observed that a younger passenger, who was seated in a priority 
seat, gave up the seat to an older passenger. However, older passengers did not always sit in a priority seat even when these seats were free. Their preference was to sit in priority seats located in the aisle, which made it difficult to enter and use the window seat due to only $0.28 \mathrm{~m}$ between cushion front and seat back; consequently this window seat was often left empty. These findings demonstrate the real-world implications of the experimental results of Petzäll (1993) who found that a short seat pitch makes it difficult to rise because the person cannot stand straight upright. Difficulties getting in and out of seats have been reported as barriers to using the bus service for older people (Broome et al. 2009). The overall importance of seating is underlined by studies that demonstrate that most bus passengers injuries occur when they are not seated (Kirk, Grant and Bird 2003).

\subsection{Critique of the study}

It was noted in section 2.4 that crowding within the buses impacted upon the quality of the data collection. The inability to record some passengers entirely and only capture partial data for others therefore results in sampling bias and likely underestimation of (1) boarding and alighting times and (2) percentage of passengers travelling standing during peak travel times. A mitigating mechanism would have been to employ video cameras to collect data relating to passenger movement, clustering and posture, which would have provided opportunity for some validation of the observational data. However, the ethics procedures applicable (and access agreements) required that passengers and driver be informed if they were being filmed. This was considered detrimental to the aim of undertaking a naturalistic observational study in this instance. The aims of the study were to investigate passenger experience in relation to bus design and broader aspects of the service, and the results above identified both driver interaction with passengers, and driving behaviour which had a detrimental impact. It is quite likely that the drivers in particular would have altered their behaviour if they had known that they, or their passengers, were being filmed.

A further cautionary note is that this type of naturalistic observational study excludes nonusers. Both older and younger passengers were typically travelling independently, did not need assistance, and only very few were using any mobility aid. It is likely that a considerable proportion of the older population with mobility issues, as well as younger disabled passengers and those with cognitive impairment, were unwilling or unable to use the bus service, and therefore did not appear in this study sample. 
In the future, further insights could be gained from undertaking objective measures which could be integrated with the observational findings to elicit a fuller understanding. For instance, measurements of biomechanical effort and muscle activation (e.g. as undertaken by Sarraf, Marigold and Robinovitch [2014]) on selected passengers would have enabled a better understanding of (1) the physical demands of boarding and alighting, and (2) the impact of lateral and longitudinal accelerations on standing stability. Similarly, the collection of sample vehicle data such as longitudinal and lateral accelerations would have established the extent to which the thresholds for balance loss for standing passengers (Palacio et al. 2009) were exceeded

\section{Conclusions}

The aim of the study was to understand how bus and service design impact differentially on younger and older passengers, within the context of a developing city. The study found key differences in the observed behaviours of younger and older passengers when using the bus service. The conditions of travel are conducive to a poor journey experience for all passengers, and specifically the safety and wellbeing of older bus passengers. There was evidence that: (1) only the most able of the older population used the buses, (2) they took significantly longer to board and alight and move to/from their seat than younger passengers, (3) they made greater use of handrails and used them to support their weight whilst boarding and alighting, (4) were still more likely to lose their balance. The older passengers employed specific strategies for coping with the demand placed on them by the bus service. These included techniques for climbing and descending the steps, preferring to sit and alight at the front of the bus, favouring the use of aisle seats over window seats and anticipatory movement towards their preferred exit prior to alighting. The key features of the bus service contributing to these behavioural differences were: bus design based on a truck chassis, poor quality roads, limited use of bus stops, and competition for passengers between operators.

Some of the problems can be attributed to the physical design of the buses which are based on a truck chassis (typical in a developing country), and in particular the high floor level and stiff suspension. The introduction of low-floor buses would reduce the physical difficulties of boarding and alighting (and has long been shown to reduce boarding times [Levine and Torng 1994]). However, some simple design changes would help the older passengers in particular, including: reducing the height of the first step; introducing more vertical and/or lower level horizontal highly visible handrails; increasing the pitch between seats; adding alighting bells 
throughout the bus and temporary stowage facilities for belongings whilst in the payment area.

Although the problems faced by older passengers in particular are exacerbated by the truckbased bus design and manner in which the buses are driven, these are influenced by the wider traffic infrastructure, behaviour of other traffic, and a lack of regulatory regime which places drivers under time pressure, and in direct competition with each other. In the short term, driver training is needed to demonstrate the impact of their actions on the safety and comfort of passengers. Training using empathic-modelling tools such as The Third Age Suit (a wearable simulation of ageing) would provide drivers with direct experience of some aspects of travelling as an older passengers and hence would increase their awareness of the challenges faced by older bus users (Hitchcock et al. 2001). Longer term, more fundamental improvements to the bus passenger experience for all passengers will require changes in the design and regulation of the broader public transport network and transport infrastructure. This should include greater bus priority, and a move towards timetabled services where profitability is not wholly contingent on picking up as many passengers within the shortest time possible. In time, service improvements will be maximised across all passengers if their diverse needs are defined and placed at the centre of an Inclusive Service Design approach.

\section{Acknowledgments}

This work was supported by the Ministry of Public Education of Mexico through the Program of Improvement of the Professors under Grant number PROMEP/1 03.5/1 0/5397.

\section{References}

ADA. 1990. “Americans with Disabilities Act.” U.S.: Department of Justice, Civil Rights Division.

Agree, Emily M, Vicki Freedman, and Manisha Sengupta. 2004. "Factors Influencing the Use of Mobility Technology in Community-Based Long-Term Care.” Journal of Aging and Health 16 (2): 267-307. doi:10.1177/0898264303262623.

Broome, Kieran, Kryss McKenna, Jennifer Fleming, and Linda Worrall. 2009. "Bus Use and Older People: A Literature Review Applying the Person-Environment-Occupation Model in Macro Practice.” Scandinavian Journal of Occupational Therapy 16 (1): 3-12. doi:10.1080/11038120802326222. 
Broome, Kieran, Emily Nalder, Linda Worrall, and Duncan Boldy. 2010. “Age-Friendly Buses? A Comparison of Reported Barriers and Facilitators to Bus Use for Younger and Older Adults.” Australasian Journal on Ageing 29 (1): 33-38. doi:10.1111/j.17416612.2009.00382.x.

Costigan, Patrick, Kevin J Deluzio, and Urs P Wyss. 2002. "Knee and Hip Kinetics during Normal Stair Climbing.” Gait \& Posture 16 (1): 31-37. doi:10.1016/S09666362(01)00201-6.

Davey, Judith. 2006. “Older People and Transport: Coping without a Car.” Ageing and Society 27 (01): 49. doi:10.1017/S0144686X06005332.

DDA. 1995. “Disability Discrimination Act.” London: The Stationery Office.

Dul, Jan, Ralph Bruder, Peter Buckle, Pascale Carayon, Pierre Falzon, William S Marras, John R Wilson, and Bas van der Doelen. 2012. "A Strategy for Human Factors/ergonomics: Developing the Discipline and Profession.” Ergonomics 55 (4): 377-95. doi:10.1080/00140139.2012.661087.

Goodpaster, B. H., S. W. Park, T. B. Harris, S. B. Kritchevsky, M. Nevitt, a. V. Schwartz, E. M. Simonsick, F. a. Tylavsky, M. Visser, and a. B. Newman. 2006. "The Loss of Skeletal Muscle Strength, Mass, and Quality in Older Adults: The Health, Aging and Body Composition Study.” The Journals of Gerontology Series A: Biological Sciences and Medical Sciences 61 (10): 1059-64. doi:10.1093/gerona/61.10.1059.

Gutiérrez-Pulido, H., M. Mariscal-González, P. Almanzor-García, M. Ayala-Dávila, V Gama-Hernández, and G. Lara-Garza. 2011. Diez Problemas de La Población de Jalisco: Una Perspectiva Sociodemográfica. Guadalajara, Mexico: COEPO, Gobierno del Estado de Jalisco.

Hamel, Kathryn, and Peter R Cavanagh. 2004. "Stair Performance in People Aged 75 and Older.” Journal of the American Geriatrics Society 52 (4): 563-67. doi:10.1111/j.15325415.2004.52162.x.

Hammersley, Martyn. 1990. "What's Wrong with Ethnography? The Myth of Theoretical Description.” Sociology 24 (4): 597-615. doi:10.1177/0038038590024004003.

Haslam, Roger, and Patrick Waterson. 2013. "Ergonomics and Sustainability.” Ergonomics 56 (3): 343-47. doi:10.1080/00140139.2013.786555.

Hitchcock, D. R., S.E. Lockyer, S.E. Cook and C.L.Quigley. 2001. "Third Age Usability and Safety - An Ergonomics Contribution to Design" International Journal of HumanComputer Studies 55((4)):635-643 doi:10.1006/ijhc.2001.0484

Hwangbo, Hwan, Jiyeon Kim, Sunwoong Kim, and Yong Ji. 2012. “Toward Universal Design in Public Transportation Systems: An Analysis of Low Floor Bus Passenger Behavior with Video Observations." Human Factors and Ergonomics in Manufacturing \& Service Industries 00 (00): 1-15. doi:10.1002/hfm. 
INEGI. 2013. Las Personas Con Discapacidad En Mexico, Una Vision Al 2010. Mexico: Intituto Nacional de Geografia y Estadistica.

Ipingbemi, Olusiyi. 2010. "Travel Characteristics and Mobility Constraints of the Elderly in Ibadan, Nigeria.” Journal of Transport Geography 18 (2). Elsevier Ltd: 285-91. doi:10.1016/j.jtrangeo.2009.05.011.

Karekla, X, and N Tyler. 2012. "Sustainable Bus Design Focused on Improved Accessibility.” In transed2012.

Katz, Donald, and Laurie A Garrow. 2012. "The Impact of Bus Door Crowding on Operations and Safety.” Journal of Public Transportation 15 (2): 71-93.

Kirk, Alan, Rachel Grant, and Richard Bird. 2003. "Passenger Casualties in Non-Collision Incidents on Buses and Coaches in Great Britain.” Proceedings of the Conference on Enhanced Safety of Vehicles (ESV) May 19-22. Nagoya, Japan, 1-10.

Levine, JC, and Gwo-Wei Torng. 1994. "Dwell-Time Effects of Low-Floor Bus Design.” Journal of Transportation Engineering 120 (6): 914-29. http://ascelibrary.org/doi/abs/10.1061/(ASCE)0733-947X(1994)120:6(914).

Levis, JA. 1978. “The Seated Bus passenger-A Review.” Applied Ergonomics 9 (3): 143-50. http://www.sciencedirect.com/science/article/pii/0003687078900042.

Maki, B E, and W E McIlroy. 1996. "Postural Control in the Older Adult.” Clinics in Geriatric Medicine 12 (4): 635-58.

Nickpour, F, P W Jordan, and H Dong. 2012. "Inclusive Bus Travel - A Psychosocial Approach.” In Designing Inclusive Systems, edited by Patrick Langdon, John Clarkson, Peter Robinson, Jonathan Lazar, and Ann Heylighen, 13-23. London: Springer London. doi:10.1007/978-1-4471-2867-0.

Osborne, JW, and Amy Overbay. 2004. "The Power of Outliers (and Why Researchers Should Always Check for Them).” Practical Assessment, Research \& Evaluation 9 (6).

Palacio, Alejandro, Giuseppe Tamburro, Desmond O’Neill, and Ciaran K Simms. 2009. "Non-Collision Injuries in Urban Buses--Strategies for Prevention.” Accident; Analysis and Prevention 41 (1): 1-9. doi:10.1016/j.aap.2008.08.016.

Pallant, Julie. 2013. SPSS Survival Manual. Berkshire, England: McGraw Hill.

Paterson, BL, JL Bottorff, and R Hewat. 2003. "Blending Observational Methods: Possibilities, Strategies, and Challenges.” International Journal of Qualitative Methods 2 (1): 29-38.

Peat, G, R McCarney, and P Croft. 2001. "Knee Pain and Osteoarthritis in Older Adults: A Review of Community Burden and Current Use of Primary Health Care.” Annals of the Rheumatic Diseases 60: 91-97. http://ard.bmj.com/content/60/2/91.short. 
Peel, Nancye, Jacky Westmoreland, and Margaret Steinberg. 2002. “Transport Safety for Older People: A Study of Their Experiences, Perceptions and Management Needs Transport Safety for Older People : A Study of Their Experiences ,." Injury Control and Safety Promotion 9 (1): 19-24.

Petzäll, J. 1993. “Ambulant Disabled Persons Using Buses: Experiments with Entrances and Seats.” Applied Ergonomics 24 (5): 313-26.

Redfern, M, R Cham, K Gielo-Perczak, R Grönqvist, M Hirvonen, H Lanshammar, M Marpet, C Y Pai, and C Powers. 2001. "Biomechanics of Slips.” Ergonomics 44 (13): 1138-66. doi:10.1080/00140130110085547.

Redfern, Mark S., Pamela L. Moore, and Christine M. Yarsky. 1997. "The Influence of Flooring on Standing Balance among Older Persons.” Human Factors 39 (3): 445-55.

Reid, Samantha M, Alison C Novak, Brenda Brouwer, and Patrick a Costigan. 2011. "Relationship between Stair Ambulation with and without a Handrail and Centre of Pressure Velocities during Stair Ascent and Descent.” Gait \& Posture 34 (4). Elsevier B.V.: 529-32. doi:10.1016/j.gaitpost.2011.07.008.

Rogers, Wendy., Beth Meyer, Neff Walker, and Arthur D. Fisk. 1998. "Functional Limitations to Daily Living Tasks in the Aged: A Focus Group Analysis.” Human Factors: The Journal of the Human Factors and Ergonomics Society 40 (1): 111-25. doi:10.1518/001872098779480613.

Sainio, Päivi, Seppo Koskinen, Markku Heliövaara, Tuija Martelin, Tommi Härkänen, Heikki Hurri, Seppo Miilunpalo, and Arpo Aromaa. 2006. "Self-Reported and Test-Based Mobility Limitations in a Representative Sample of Finns Aged 30+.” Scandinavian Journal of Public Health 34 (4): 378-86. doi:10.1080/14034940500489859.

Sarraf, Thiago, Daniel S Marigold, and Stephen N Robinovitch. 2014. "Maintaining Standing Balance by Handrail Grasping.” Gait \& Posture 39 (1). Elsevier B.V.: 258-64. doi:10.1016/j.gaitpost.2013.07.117.

Startzell, JK, and DA Owens. 2000. “Stair Negotiation in Older People: A Review.” Journal of the American Geriatrics Society 48: 567-80.

Stevens, JP. 2009. Applied Multivariate Statistics for the Social Sciences. 5th Editio. New York: Taylor \& Francis.

Tiedemann, Anne C, Catherine Sherrington, and Stephen R Lord. 2007. "Physical and Psychological Factors Associated with Stair Negotiation Performance in Older People.” The Journals of Gerontology. Series A, Biological Sciences and Medical Sciences 62 (11): 1259-65.

United Nations. 2002. “Madrid International Plan of Action on Ageing.” New York: United Nations.

United Nations. 2010. “World Population Ageing Report 2009.” New York: United Nations. 
WHO. 2002. “Active Ageing. A Policy Framework.” Geneva: WHO.

WHO. 2007. Global Age-Friendly Cities: A Guide. WHO.

Zeedyk, M Suzanne, and Laura Kelly. 2003. "Behavioural Observations of Adult-Child Pairs at Pedestrian Crossings.” Accident; Analysis and Prevention 35 (5): 771-76. 